\section{Cognition: evolution does help to explain how minds work}

SIR — In their Essay 'Can evolution explain how minds work?' (Nature 458, 832-833; 2009), Johan Bolhuis and Clive Wynne use Darwin's claim that there is "no fundamental difference between man and the higher mammals in their mental faculties" to explain how people have gone down the wrong path in studying cognition. But in homing in on examples of convergent evolution, in which humans and some distantly related species such as songbirds seem to have come up with similar solutions to the same problem, Bolhuis and Wynne neglect one key feature that distinguishes humans from all other animals.

The feature that is peculiar to humans is their understanding about the causal interactions between physical objects (see, for example, L. Wolpert Six Impossible Things Before Breakfast; Faber, 2006). For example, children realize from an early age that one moving object can make another move on impact. It is this primitive concept of mechanics that is a crucial feature of causal belief, and that conferred an advantage in tool-making and the use of tools - which, in turn, drove human evolution.

Animals, by contrast, have very limited causal beliefs, although they can learn to carry out complex tasks. According to Michael Tomasello (The Cultural Origins of Human Cognition; Harvard Univ. Press, 1999), only human primates understand the causal and intentional relations that hold among external entities. Tomasello illustrates this point for non-human primates with the claim that even though they might watch the wind shaking a branch until its fruit falls, they would never shake the branch themselves to obtain the fruit. Some primates are, nevertheless, at the edge of having causal understanding.
Once causal belief evolved in relation to tools and language, it was inevitable that people would want to understand the causes of all the events that might affect their lives - such as illness, changes in climate and death itself. Once there was a concept of cause and effect, ignorance was no longer bliss, and this could have led to the development of religious beliefs. Lewis Wolpert Department of Cell and Developmental Biology, University College London, London WC1E 6BT, UK

e-mail: I.wolpert@ucl.ac.uk

\section{Cognition: theories of mind in animals and humans}

SIR - I believe that Johan Bolhuis and Clive Wynne, in their Essay

'Can evolution explain how minds work?' (Nature 458, 832-833;

2009), profoundly misrepresent the burgeoning interdisciplinary field of comparative cognition research as being rife with anthropomorphism and ignorance of evolutionary principles.

Darwinism in animal cognition is represented, not by the naive anthropomorphism practised by Darwin and his contemporaries, but by Darwin's claim that humans differ mentally from other species "in degree but not in kind". There is evidence from behavioural studies that many of humans' mental powers are shared by other animals, including simple forms of learning, memory and categorization, and the elements of social, spatial and numerical cognition.

Only against this background does it make sense to propose, as some have, that there is a distinct small set of mental powers that is unique to humans, including theory of mind (see, for example, D. C. Penn et al. Behav. Brain Sci. 31, 109-178; 2008). Contrary to what Bolhuis and Wynne are suggesting, careful analysis of the behaviours taken as evidence for theory of mind in species from chimpanzees to dogs to birds has led to a rethink of claims that were initially anthropomorphic.

The authors suggest that relatedness among species is emphasized at the expense of convergently evolved cognitive similarities. On the contrary: apparently similar performances of distantly related species - as in tool-using, social cognition and teaching-like behaviour - are now increasingly being studied precisely because convergence is a recognized test-bed for functional hypotheses. For example, the proposal that monkeys and apes have evolved exceptional social skills to navigate a particular kind of social group is tested with non-primate species that have complex social organization, such as hyenas, some birds and even fish. Comparison of the cognitive mechanisms underlying such functionally similar behaviours is an active area of research.

Bolhuis and Wynne end with the proposal that we should "study animal and human minds empirically" - as if that is not already being done (for an overview, see S. J. Shettleworth Behav. Processes 80, 210-217; 2009). As they point out, evolution cannot explain how minds work (any more than it can explain precisely how nerves or genes work), and our own psychology can be an obstacle to understanding that of other species.

Nevertheless, studying minds in their phylogenetic and functional context can provide an indication of what they were selected to do. And, as in the other biological sciences, it can offer a theoretical framework for meaningful comparative research into mechanisms.

Sara J. Shettleworth Department of Psychology, University of Toronto, 100 St George Street, Toronto, Ontario M5S 3G3, Canada e-mail: shettle@psych.utoronto.ca

\section{John Maddox and the Medical Research Council}

SIR - In his Obituary 'Maddox by his successor' (Nature 458, 985-986; 2009), Philip Campbell describes an account given by the former editor of Nature, John Maddox, of how he walked out of a meeting of the UK Medical Research Council (MRC) when he realized he had been summoned to defend his public criticisms of that institution. In fact, Maddox was never asked to attend a meeting of the MRC. In my ten years as MRC secretary, and my time as a member of the council during Harold Himsworth's tenure as secretary, the council has never "summoned" anyone to a meeting to "defend" their criticisms, and indeed they never would.

Maddox must have been referring to the occasion (about which I never informed the council, before or after the event) when I asked him if he would like to drop into the MRC office to hear why I had asked two individuals to consider withdrawing letters that they had sent to Nature for publication. The letters, of which the authors had sent me copies, were about a clinical trial we planned to carry out in women who had had a child with the birth defect spina bifida. I had thought, perhaps mistakenly, that the two letters might further increase the growing public and political opposition to the trial, which was threatening to prevent its launch.

When Maddox came to the MRC office, he simply handed me a copy of the next week's Nature, pointing out a blank column where the letters might have appeared (Nature 300, 310; 1982). I handed it back and he left with hardly a word (certainly not a discourteous word) passing between us. In that sense, he did "walk out".

James Gowans Cumnor Hill, Oxford OX2 9HX, UK e-mail: jamesgowans@btinternet.com

The Nature John Maddox special is at www.nature.com/jm 